\title{
Letter to the Editor: Study of Live Lecture Attendance, Student Perceptions and Expectations
}

\author{
Abyrami Sivanandarajah $^{1}$ (I) $\cdot$ Tharunica Thavajothy $^{2} \cdot$ Sloni Arora $^{2}$
}

Accepted: 3 September 2021 / Published online: 16 September 2021

(c) International Association of Medical Science Educators 2021

\section{Dear Editor,}

We read with great interest the article by Emahiser et al. which investigates the reasons for declining live lecture attendance among undergraduate medical students [1]. As final year medical students at British medical schools, we full-heartedly support the authors view that carefully tailored active learning sessions may improve live lecture attendance.

In the article by Emahiser et al., active learning modalities had higher satisfaction rates among medical students over traditional lecture-based learning [1]. Peninsula Medical School has moved away from didactic teaching, adopting a type of active learning modality called problem-based learning (PBL). PBL encourages critical thinking skills, analytic skills and decision-making $[2,3]$. We feel that this is a better suited style of learning for medical students as it helps us demonstrate our practical application of knowledge onto clinical scenarios. We also agree that the possible main contributor to poor live lecture attendance is whether lecture material is beneficial to Board exam learning [1]. As medical students, we understand that time is valuable and attending lectures that do not meet our academic needs to pass Board exams is counterintuitive towards our learning.

We recommend the authors consider the impacts of monitoring attendance to improve live lecture attendance. At Peninsula Medical School, lecture attendance is mandatory. As also explained in Emahiser et al., our medical school faculty became increasingly concerned about the

Abyrami Sivanandarajah

Abyrami.sivanandarajah@students.plymouth.ac.uk

1 Faculty of Medicine and Dentistry, University of Plymouth, John Bull Building, Plymouth Science Park, Research Way, Plymouth PL6 8BT, UK

2 Faculty of Life Sciences and Medicine, King's College London Guy's Campus, London SE1 1UL, UK poor levels of student attendance and professionalism [1]. Thus, lectures became diligently monitored by assigned staff, which has drastically improved cohort attendance but at the cost of the cohort's morale. Repercussions for non-attendance may include warning emails, an academic tutor meeting and further escalation with the professionalism lead. These reprimands might seem menial; however, the fear of this affecting medical school progression is grave enough to cut losses and attend lectures no matter the value to learning. We feel that student attendance on par with student learning should be entrusted to students, as explained in Lamb et al. [4]. Faculties should support students in meeting their educational needs in passing Board exams and not patrol them for their lecture attendance.

It is undeniable that the COVID-19 pandemic has disrupted medical education [5]. We feel the author should consider the added challenges brought by this. Internet issues, administrative problems and poor time management are new factors that may heavily impact live lecture attendance. We anticipate that this shift towards remote learning will prove to be the new norm for the foreseeable future.

\section{References}

1. Emahiser J, Nguyen J, Vanier C, et al. Study of live lecture attendance, student perceptions and expectations. Med Sci Educ. 2021;31:697-707. https://doi.org/10.1007/s40670-021-01236-8.

2. Khoshnevisasl P, Sadeghzadeh M, Mazloomzadeh S, et al. Comparison of problem-based learning with lecture-based learning. Iran Red Crescent Med J. 2014;16(5): e5186. https://doi.org/10. 5812/ircmj.5186.

3. Preeti B, Ashish A, Shriram G. Problem based learning (PBL) an effective approach to improve learning outcomes in medical teaching. J Clin Diagn Res. 2013;7(12):2896-7. https://doi.org/ 10.7860/JCDR/2013/7339.3787.

4. Lamb S, Chow C, Lindsley J, et al. Learning from failure: how eliminating required attendance sparked the beginning of a 
medical school transformation. Perspect Med Educ. 2020;9:3147. https://doi.org/10.1007/s40037-020-00615-y.

5. Alsoufi A, Alsuyihili A, Msherghi A, et al. Impact of the COVID19 pandemic on medical education: medical students' knowledge, attitudes, and practices regarding electronic learning. PLoS One. 2020;15(11):e0242905. https://doi.org/10.1371/journal.pone. 0242905 .

Publisher's Note Springer Nature remains neutral with regard to jurisdictional claims in published maps and institutional affiliations. 